\title{
PARTIALLY HYPER INVARIANT SUBSPACES
}

\author{
Slaviša DJORdJEVic, Robin Harte AND DAVID LARSON
}

Abstract. Between invariance and hyperinvariance are at least two other kinds of partially hyperinvariant subspace.

Mathematics subject classification (2010): Primary 47A15; secondary 47A10, 47A60. property.

Keywords and phrases: invariant subspace, hyperinvariant subspace, spectrally invariant, three space

\section{REFERENCES}

[1] B.A. BARNES, Spectral and Fredholm theory involving the diagonal of a bounded linear operator, Acta Sci Math. (Szeged) 73 (2007), 237-250.

[2] R. Crownover, Commutants of shifts on Banach spaces, Michigan Math. Jour 19 (1972), $233-247$.

[3] R.V. Garimella, V. Hrynkiv And A.R. Sourour, An operator equation, KdV equation and invariant subspaces, Proc. Amer. Math. Soc. 138 (2010), 717-724.

[4] R.E. HARTE, Invertibility and singularity, Dekker 1988.

[5] R.E. HARTE, Taylor exactness and Kaplansky's lemma, Jour. Op. Th. 25 (1991), 399-416.

[6] R.E. HARTE, Block diagonalization in Banach algebras, Proc. Amer. Math. Soc. 129 (2000), 181190.

[7] R.E. Harte, C. Hernandez And C.M. Stack, Exactness and the Jordan form, Funct. Anal. Approx. Comp. 3 (2011), 1-7.

[8] R.E. Harte And C.M. Stack, Separation of spectra for block triangles, Proc. Amer. Math. Soc. 136 (2008), 3159-3162.

[9] V. MÜLLER, Spectral theory of linear operators, Operator Theory: Adv. Appl. 139 (2007).

[10] H. RadjaVi And P. Rosenthal, Invariant subspaces, Springer 1973. 